\title{
Temporal and Spatial Analysis of Coastline Changes in the Bohai Rim Based on RS and GIS
}

\author{
Xu Jinyong, Zhang Zengxiang, Zuo Lijun, Wen Qingke, Liu Bin \\ Institute of Remote Sensing and Digital Earth \\ Chinese Academy of Sciences \\ Beijing, China \\ xu_jy@irsa.ac.cn
}

\begin{abstract}
Remote sensing and GIS technology was adopted to monitor temporal and spatial distribution of continental coastline in the Bohai Rim from 2000 to 2008. Moreover, this paper has analyzed the fractal dimension change of coastline. Both the length and fractal dimension of the coastline in Bohai Rim increased from 2000 to 2008, which were mainly caused by human disturbances. Regional difference of coastline change was significant, especially the length change intensity of coastlines in Tianjin City and Hebei Province were relatively higher. Expansion of port and dock, construction of port-surrounding industrial park as well as development of breeding pond and saltworks were the main artificial disturbance factors for change of coastline in the Bohai Rim.
\end{abstract}

Index Terms - the Bohai Rim, coastline, remote sensing.

\section{INTRODUCTION}

The coastline not only marks the sea-land boundary in coastal areas but also contains a wealth of environmental information. Changes in coastlines directly affect the resources of intertidal flats and the environment in coastal zones; moreover, these changes will cause variations in a variety of resources and ecological processes in coastal zones that affect the survival and development of coastal residents[1,2]. The coastal zone is sensitive to global change; thus, the study of coastline changes and their driving factors is of great significance for understanding not only ecological environment variations in coastal zones but also global changes[3-6].

Remote sensing has advantages over other techniques for surface examinations because remote sensing can provide macroscopic, fast, and repeated observations of surface information. Using remote sensing and geographic information system (GIS) techniques, coastline information can be quickly and accurately extracted and dynamically monitored, thereby allowing the impact of sea-area utilization on coastlines to be understood in a timely manner[7-8].

After the Pearl River Delta and Yangtze River Delta regions, the Bohai Rim, which has been a hot spot of economic development in China in recent years, is the new engine of China's economic development. In provinces and cities of the Bohai Rim, growth is occurring in various marine development activities, such as fisheries, ocean shipping, petroleum, natural gas, and sea-salt extraction operations, among other pursuits[9].
Meanwhile, numerous major rivers in northern China flow into the Bohai Sea, including the Yellow River, Hai River, Luan River, and Daliao River, among others. Changes in natural conditions, including (but not limited to) siltation and erosion due to estuaries, and the influences of human actions, will inevitably cause constant changes in coastlines and thereby affect the coastal environment.

The visual interpretation method was employed to extract the spatial and temporal distribution of the continental coastlines of 2000, 2005 and 2008 in Bohai Rim, and grid method was applied to calculate the fractal dimensions of the coastlines. Besides, factors that cause coastline change were also analyzed. From north to south, the coastline of Bohai Rim starts at the Laotieshan corner of Liaodong peninsula, terminates at the most northern of the Penglai in Shandong peninsula, the longitude is between $117^{\circ} 35^{\prime} \mathrm{E}$ and $122^{\circ} 20^{\prime} \mathrm{E}$, and latitude is between $37^{\circ} 05^{\prime} \mathrm{N}$ and $40^{\circ} 30^{\prime} \mathrm{N}$ (Fig. 1).

\section{RESEARCH METHOD}

\section{A. Definition of coastline}

In this study, in accordance with the "908 Project" definition, the coastline was regarded as the line that traces the boundary between land and sea during an average spring high tide[10]. Coastlines may be divided into continental coastlines and island coastlines, and this study only examined the spatial and temporal variation of continental coastlines in Bohai Rim.

\section{B. Method of coastline interpretation}

\section{1) Acquisition and disposal of remote sensing data}

It mainly depends on landsat TM data and CBERS CCD data. The spatial resolution of the TM data was $30 \mathrm{~m}$, and the spatial resolution of the CBERS CCD data was $19.5 \mathrm{~m}$; both of two resolutions satisfy the requirements for 1:100,000 mapping. Remote-sensing images from all of the examined times were compared with topographic maps for geometric corrections, and the error was never greater than 1 pixel of image.

Auxiliary data used in this study primarily include topographic maps, administrative maps, and local history; a field survey of coastline types on the Bohai Rim was also conducted to provide important supporting information for the interpretation of the coastline remote-sensing data. 
2) Method of extracting coastlines from remote-sensing images

The position of the coastlines in the study area was comprehensively analyzed and visually interpreted from various features of standard false-color remote-sensing images, such as tones, textures, spatial morphologies, and distribution characteristics, references to topographic maps of the study area, field observations, and other supplementary information. Different interpretation standards were applied for the remote sensing of coastlines of different coast types[7,11-12].

In particular, artificial coasts directly border seawater and generally feature regular land-sea demarcation lines; the sea side of the artificial coast was regarded as the artificial shoreline. For sandy coasts that are generally flat, sandy sediments are carried by the spring tide and often deposited to form a ridge that is parallel to the shore; the position of this ridge was regarded as the location of the coastline. For muddy coasts that have been developed or encompass a relatively small area, the coastline was regarded as the dividing line between tidal flats and other surface features, such as vegetation, shrimp ponds, and roads, because at the height of spring tide, seawater cannot cross this dividing line. For muddy coasts without artificial development, the exposed land above the average high tide line during spring tides and the tidal flat below the average high tide line during spring tides will typically be portrayed in different colors in remote-sensing images; the dividing line between these two types of land was regarded as the coastline. For bedrock coast, the locations of direct sea-land contact between ocean capes and upright cliffs were regarded as the coastline.

To ensure that the unchanged portions of the coastlines were strictly consistent in position between two consecutive time periods, the coastline distribution in 2000 was visually interpreted and digitized using the ArcInfo software platform to generate the Coverage vector data. Subsequent coastline measurements used the earlier coastline as the fundamental data, and only the changed portions of coastlines were dynamically updated. This approach effectively avoided the "double eyelid" phenomenon that would occur if the coastline dynamics had been directly extracted from remote-sensing images with different spatial resolutions that had been obtained at different times.

3) Method of calculating the fractal dimensions of coastlines

The grid method was adopted to calculate these fractal dimensions. The fundamental notion of the grid method is to use non-overlapping square grids of different lengths to continuously cover the coastline that must be measured. When the length of the square grid $\left(\varepsilon_{k}\right)$ changes, the number of grids needed to cover the entire coastline, $N_{k}\left(\varepsilon_{k}\right)$ will shift accordingly. According to fractal theory:

$$
N_{k}\left(\varepsilon_{k}\right) \propto \varepsilon_{k}^{-D}
$$

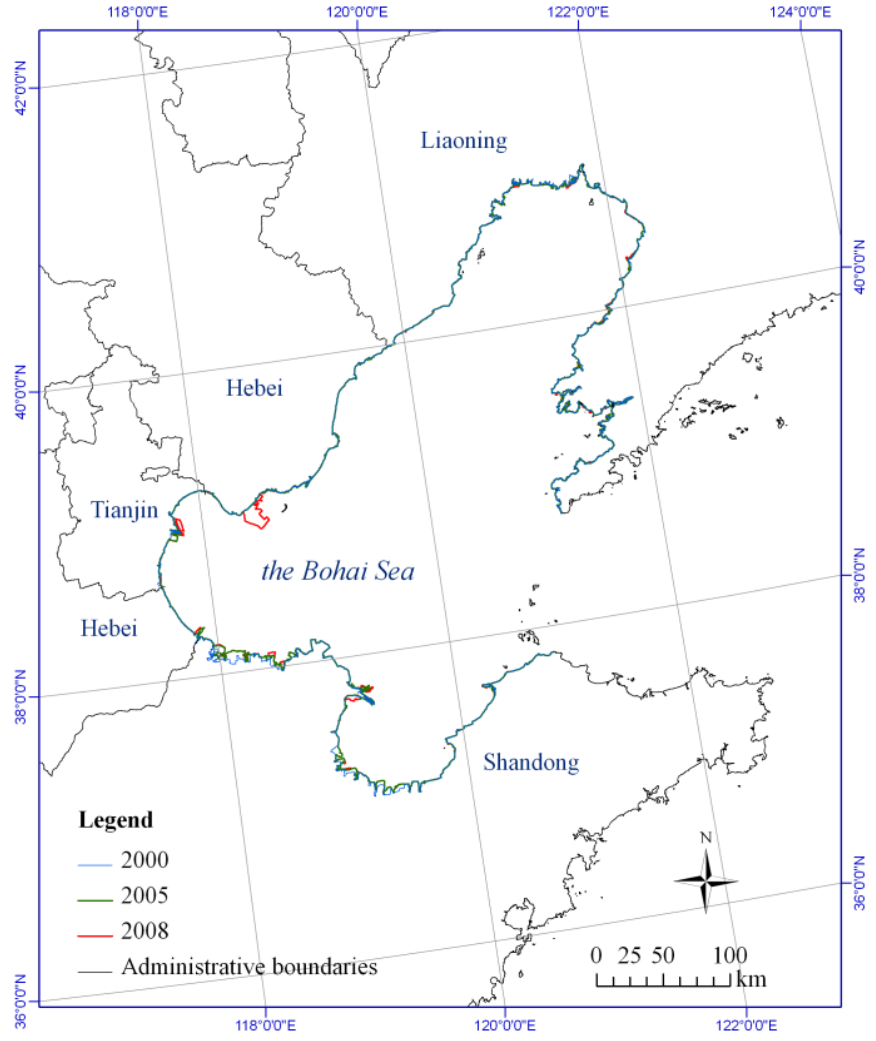

Fig. 1. Spatial distribution of coastline in the Bohai Rim

\section{Coastline change from 2000 to 2008}

From 2000 to 2008, the coastline length of the Bohai Rim has increased by $195.89 \mathrm{~km}$, an average of $24.49 \mathrm{~km}$ per year during the monitoring periods. Among the examined areas, the greatest changes in coastline length occurred in Hebei Province, where the coastline length increased by $74.67 \mathrm{~km}$, an average increase of $9.33 \mathrm{~km}$ per year; followed by Liaoning Province, where coastline length increased by $53.66 \mathrm{~km}$, an average of $6.71 \mathrm{~km}$ per year; Shandong Province, where coastline length increased by $35.28 \mathrm{~km}$, an average of $4.41 \mathrm{~km}$ per year, and; finally, Tianjin City, which had the smallest coastline length increase of $32.29 \mathrm{~km}$, an average of $4.04 \mathrm{~km}$ per year.

The coastline of 2005 in Bohai Rim increased by $128.34 \mathrm{~km}$ when compared with that of 2000, with an average increase of $25.67 \mathrm{~km}$ per year; the coastline of 2008 in Bohai Rim increased by $67.55 \mathrm{~km}$ when compared with that of 2005, with an average increase of $22.52 \mathrm{~km}$ per year. Therefore, the increase rate of the Bohai Rim has slowed $3.15 \mathrm{~km}$ per year.

During the monitoring period from 2000 to 2005, the changing scope mainly focuses on Laizhou Bay, seacoast of Binzhou, Cangzhou, Tianjin and Tangshan, as well as the Liaodong Bay; there are few changes in other coastal sections. During the monitoring period from 2005 to 2008, the changing scope is generally similar to that from 2000 to 2005 , but coastline 
change along the Tianjin - Tangshan bank was more prominent; coastline change in other sections was not so obvious when compared with that from 2000 to 2005.

\section{1) Annual length change of coastline in the Bohai Rim}

Except that the coastline length in Shandong Province decreased from 2005 to 2008, coastline length of all other regions presented an increase trend from 2000 to 2005 and from 2005 to 2008. Decrease of coastline length in Shandong Province from 2005 to 2008 was mainly caused on muddy coast. The order of absolute value for annual coastline length change from 2000 to 2005 was: Shandong Province > Liaoning Province > Hebei Province > Tianjin City; that of period from 2005 to 2008 was: Hebei Province $>$ Tianjin City $>$ Shandong Province $>$ Liaoning Province. Therefore, the rate of costline change in Tianjin City and Hebei Province were accelerated during the period from 2005 to 2008, while the situation for Liaoning Province and Shandong Province was contrary.

\section{2) Length change intensity of coastline in the Bohai Rim}

There were differences among the coastline lengths of the examined regions in Bohai Rim. To objectively compare the spatial and temporal differences in the rate of coastline length change in various periods, the average annual percentage of variation in coastline length during a particular period was used to represent the intensity of the coastline change during the period in question

$$
L C I_{i j}=\frac{L_{j}-L_{i}}{L_{i} \times(j-i)} \times 100 \%
$$

Where LCI (Length Change Intensity) indicates the length change intensity of coastline length in particular region, $L_{i}$ represents the coastline length of $\mathrm{i}$ year, and $L_{j}$ represents the coastline length of $\mathrm{j}$ year.

The order of absolute value for coastline length change intensity from 2000 to 2005 was: Hebei Province > Shandong Province > Tianjin City > Liaoning Province; that for period from 2005 to 2008 was: Tianjin City > Hebei Province > Shandong Province $>$ Liaoning Province (Table.2). This shows that the coastline length change in Tianjin City and Hebei Province was relatively fierce.

\section{Fractal dimension change of coastline in the Bohai Rim}

To ensure the continuous integrity of the coastline, in the calculation of the fractal dimension of the coastlines of the Bohai Rim with the grid method, the coastlines of Tianjin City and Hebei Province were combined into the Tianjin \& Hebei area (Table.3).

Among the regions in the study area, the geometries of the coastlines were most complicated in Liaoning Province, followed by Shandong Province and the Tianjin \& Hebei area.

The fractal dimension of the overall coastline of study area was always among the fractal dimensions of the Tianjin \& Hebei area, Liaoning Province, and Shandong Province coastlines. This fractal dimension value was not equal to the average of the fractal dimensions of the individual coastline segments. Instead, the overall fractal dimension value was close to the maximum of the fractal dimensions of the coastlines of each individual segment; this result is consistent with the findings of previous research regarding the fractal dimensions of coastlines [14].

From 2000 to 2008, the fractal dimension of the overall coastline of the study area steadily increased, indicating that the geometry of the coastline of the study area became more complex. The fractal dimensions of the coastlines in the Tianjin \& Hebei area and Liaoning Province tend to vary in accordance with the changes in the overall coastline. In contrast, the fractal dimension of coastline in Shandong Province decreased during the period from 2005 to 2008 . In general, relatively intense variation in the fractal dimension of the Tianjin \& Hebei coastline was observed, increase by 0.0198 from 2000 to 2008, whereas the fractal dimensions of the Liaoning Province and Shandong Province coastlines remained relatively stable, increase by 0.0055 and 0.0161 respectively.

TABLE I. LENGTH CHANGE INTENSITY OF COASTLINE

\begin{tabular}{|c|c|c|l|l|l|}
\hline \multirow{2}{*}{ Year } & \multicolumn{5}{|c|}{ Region } \\
\cline { 2 - 6 } & Tianjin & Hebei & Liaoning & Shandong & Overall \\
\hline $2000-2005$ & $1.14 \%$ & $1.51 \%$ & $0.59 \%$ & $1.31 \%$ & $0.99 \%$ \\
\hline $2005-2008$ & $5.15 \%$ & $3.98 \%$ & $0.46 \%$ & $-0.76 \%$ & $0.83 \%$ \\
\hline
\end{tabular}

TABLE II. FRACTAL DIMENSION CHANGE OF COASTLINE IN THE BOHAI RIM

\begin{tabular}{|l|l|l|l|l|}
\hline \multirow{2}{*}{ Year } & \multicolumn{4}{|c|}{ Region } \\
\cline { 2 - 5 } & \multicolumn{1}{|c|}{ Tianjin \& Hebei } & \multicolumn{1}{|c|}{ Liaoning } & Shandong & Overall \\
\hline 2000 & 1.0628 & 1.1075 & 1.0821 & 1.1029 \\
\hline 2005 & 1.0723 & 1.1124 & 1.1016 & 1.1111 \\
\hline 2008 & 1.0826 & 1.1130 & 1.0982 & 1.1127 \\
\hline
\end{tabular}

\section{E. Analysis on reasons of the Bohai Sea coastline change}

Coastal tourism, marine fisheries, oil and gas industry, salt chemistry and marine transportation ranked before for the development of coastal economy surrounding Bohai Rim[15], A large number of artificial projects were the main cause of coastline change in the Bohai Rim, including expansion of port and dock, construction of port-surrounding industrial park, development of breeding pond and saltworks, etc. Compared with human disturbance, natural changes such as the process of erosion and siltation which mainly occurred in the Yellow River mouth region had little influence on the overall coastline in the Bohai Rim.

Port resource superiority in the Bohai Rim is obvious, and it has the densest port group in China. From the border of Penglai to the south of Lushun, there are dozens of ports. By a case study of Caofeidian industrial park in Hebei Province, Caofeidian is 
located on the west bank of Bohai Rim in the south of Tangshan City, which has advantaged conditions for development of largescale deepwater port and port-surrounding industry. According to remote sensing monitoring, construction of Caofeidian harbor district has increased the coastline length by $53.39 \mathrm{~km}$ from 2000 to 2008 .

Human project has influenced the fractal dimension of coastline in the Bohai Rim also, because large number of smallscale coastal engineering could increase the fractal dimension of coastline, while the engineering of large scale that made the coastline straight will reduce fractal dimension[16].

\section{CONCLUSION}

Main dynamic characteristics of coastline in the Bohai Rim from 2000 to 2008 were:

(1) Overall length of coastline in the Bohai rim increased gradually from 2000 to 2008, which was mainly caused by human disturbances.

(2) The length change intensity of coastline in Tianjin City and Hebei Province during the monitoring period was relatively fierce. Moreover, the length change intensity of coastline in Tianjin City and Hebei Province from 2005 to 2008 was higher than that from 2000 to 2005.

(4) Among the regions in the study area, the geometries of the coastlines were most complicated in Liaoning Province, followed by Shandong Province and the Tianjin \& Hebei area.

(5) From 2000 to 2008, the fractal dimension of the overall coastline of the Bohai Rim steadily increased, indicating that the geometry of the coastline of the Bohai Rim became more complex. In general, relatively intense variation in the fractal dimension of the Tianjin \& Hebei coastline was observed,

(6) Expansion of port and dock, construction of portsurrounding industrial park as well as development of breeding pond and saltworks were the main artificial disturbance factors for coastline change in Bohai Rim.

\section{ACKNOWLEDGMENT}

The study was sponsored by National 908 Project(No. 2010CB95090102).

\section{REFERENCES}

[1] Cai Z J and Wu S L, "Remote sensing analysis of the coastline development in Jiangsu province," REMOTE SENSING FOR LAND \& RESOURCES, vol.53, pp. 19-23, September 2002.

[2] Tao M G, "Interpretation of coastline changes based on LandsetTM remote sensing images: an example of the mouth area of Jiulongjiang River," Hydrogeology \& Engineering Geology. vol.1, pp. 107-110, January 2006.
[3] Yu Y H, Miao F M, Wang Y G, Wang Q M, Wang J, Gao S G, "Study on application of $3 \mathrm{~S}$ techniques in coastline surveying and managing," Geography and Geo-Information Science, vol.19, pp. 24-27, November 2003.

[4] Ou W X, Yang G S, Yu X X, Li H P, "Effect of coastal land use changes on eco-environment in the coastal zone of Yancheng," RESOURCES SCIENCE, vol.26, pp. 77-83, May 2004.

[5] Antonio Jabaloy-Sánchez, Francisco José Lobo, Antonio Azor, Patricia Bárcenas, Luis Miguel Fernández-Salas, Víctor Díaz del Río, et al., "Human-driven coastline changes in the Adra River deltaic system, southeast Spain," Geomorphology, vol.119, pp. 922, February, 2010.

[6] Sabyasachi Maiti, Amit K. Bhattacharya, "Shoreline change analysis and its application to prediction: A remote sensing and statistics based approach," Marine Geology, vol.257, pp. 11-23, 2009.

[7] Sun W F, Ma Y, Zhang J, Liu S W, Ren G B, "Study of remote sensing interpretation keys and extraction technique of different types of shoreline," Bulletin of Surveying and Mapping, vol.3, pp. 41-44, March 2011.

[8] Li J and Zhang Y, "Analysis of coastline change based on remote sensing measurement," Journal of Hohai University(Natural Sciences), vol.40, pp. 224-228, March 2012.

[9] Liu R Z and Wu S S, "Situation and potential perils of the economic development in the Bohai Sea Rim," China Population. Resources and Environment, vol.18, pp. 55-59, March 2008.

[10] Office of the State Oceanic Administration 908 special. "Regulations of Coastal Investigation Techniques," China Ocean Press, Beijing, pp. 1-2, 2005.

[11] Chang J, Liu G H and Liu Q S, "Dynamic monitoring of coastline in the Yellow River Delta by remote sensing," Geo-Information Science, vol.6, pp. 94-98, March 2004.

[12] Ma X F, Zhao D Z, Xing X G, Zhang F S, Wen S Y, Yang F, "Means of withdrawing coastline by remote sensing," Marine Environmental Science, vol.26, pp. 185-189, April 2007.

[13] Han X P, Fu X M, Tang J Y, Liao B G, "Fractal method for correcting the length of the map curves," Journal of East China Normal University (Natural Science), vol. (6):34-40, November 2006.

[14] Zhu X H, Wang J, Chen X, "Study on the spatial fractal characteristic of coastline: A case study of Jiangsu Province, China," Scientia Geographica Sinica, vol.21, pp. 70-75, Februry 2001.

[15] Fang S, Ji J Y, Lin Z F, "The selection of pillar industry on marine economy of the area surrounding Bohai Sea," Science of Science and Management of S. \& T., vol6, pp. 127-130, June 2007.

[16] Ye X M, Ji Y Q, Zheng A Q, Wu Y S, Hua F, Lin Z S, "Fractal analysis of the coastline changes of the Jiaozhou Bay," ADVANCES IN MARINE SCIENCE, Vol.27, pp. 495501, October 